\title{
Recovery Pattern of Dysphagia in Lateral Medullary Infarction- A Case Report
}

\author{
K Govathi Nikhila*, Akanksha Gupta, Sushant Bhuyan and Arun Garg \\ Medanta- The Medicity Hospital, Department of Neurosciences, India
}

Submission: December 29, 2016; Published: January 09, 2017

*Corresponding author: K Govathi Nikhila, TRT122/A, Seethaphalmandi, Secunderabad, Telangana, 500061, India, Tel: 9582972948 ;

Email: gnikhilaks@gmail.com

Abstract

This report concerns about a $75 \mathrm{yrs}$, old male suffered from refractory dysphagia after Acute Ischemic stroke. He admitted in Medanta Hospital in emergency ward with History of Acute Ischemic stroke- Right Lateral Medullary Infarct, Aspiration Pneumonitis and sepsis (resolved). After 5 days the patient received clinical bed side swallow evaluation and graded with Level-1 based on National Outcomes measurements systems (NOMS) and was showing with severe Aspiration. Then he recommended for intensive swallow therapy but the patient was discharged on Level-1 based on NOMS and stopped doing the exercises then later after 2months he came to the hospital and received combined swallow therapy and achieved a good improvement in deglutition and was graded with level-7 based on NOMS.

Conclusion: combination of vital stim electrical therapy and swallow therapy has greater effect on deglutition disorder in patients with LMS.

Abbreviations: NOMS: National Outcomes measurements systems; WA: Wallenberg's Syndrome; VA: Vertebral Artery; PICA: Posterior Inferior Cerebellar Artery; NTS: Nucleus Tractus Solitaries; NA: Nucleus Ambiguous; LMS: Lateral Medullary Stroke; NMES: Neuromuscular Electrical Stimulation; RTF: Ryle's Tube Feeding; NG tube: Nasogastric tube; NJ: Nasojejunal Tube; FDA: Food and Drug Administration; GCS: Glasgow Coma Scale; MRI: Magnetic Resonance Imaging; CT: Computed Tomography

\section{Introduction}

In 1808 Gaspard was the person who invented the term Lateral medullary syndrome. The lateral medullary syndrome (Wallenberg's syndrome) is most often caused by occlusion of the intracranial segment of the vertebral artery (VA), less commonly; it is caused by occlusion of the posterior inferior cerebellar artery (PICA). The syndrome is characterized by sensory deficits affecting the trunk and extremities on the opposite side of the infarction and sensory deficits affecting the face and cranial nerves on the same side with the infarct. Specifically, there is a loss of pain and temperature sensation on the contralateral side of the body and ipsilateral side of the face. Crossed findings are like diagnostic tool for Lateral medullary syndrome. In LMS other clinical symptoms and signs are deglutition difficulties (Swallowing difficulty) [1,2], slurred speech, ataxia, facial pain, vertigo, nystagmus, Horner's syndrome, diplopia and possibly palatal myoclonus.

The person with LMS commonly results with deglutition disorder which may result with involvement of the nucleus ambigus as well as dysarthria. Damage to the spinal trigeminal nucleus causes absence of pain on the ipsilateral side of the face as well as absence corneal reflex. A brainstem stroke affects the functioning of deglutition, as it plays a major role with deglutition centers like nucleus tractus solitarius (NTS), nucleus ambiguous (NA), and the reticular formation are situated in the dorsolateral medulla oblongata [3]. As a result, Deglutition disorder following a lateral medullary stroke (LMS) is often more severe and spontaneous recovery may not completely restore the deglutition function. It may persist for life time or months or years to resolve [4]. The size and site of lesion through MRI imaging can play a significant role in determining deglutition disorder morbidity. However, the MRI results can only determine the area of infarction and not the phases/ structures of deglutition and also can't clarify the variation of deglutition disorders among patients with LMS.

Deglutition disorder is one of the perplexing symptoms of many neurologic diseases. The early diagnosis and rehabilitation of Deglutition disorder is to avoid aspiration, pneumonia, dehydration, malnutrition and sepsis, which are potentially fatal complications .The prognosis of deglutition disorder depends on the disease type, and can vary from no improvement to the recovery of normal feeding [2,5-7]. During the normal deglutition process, the brainstem regulates signals from the 
cerebrum, to the oral cavity and pharyngeal region to allow the bolus to transit in a safely pathway. The deglutition centers of cerebrum are in the sensorimotor cortex, the prefrontal cortex, and the insular region, and the right hemisphere is known to participate more than the left $[8,9]$ (Figure 1).

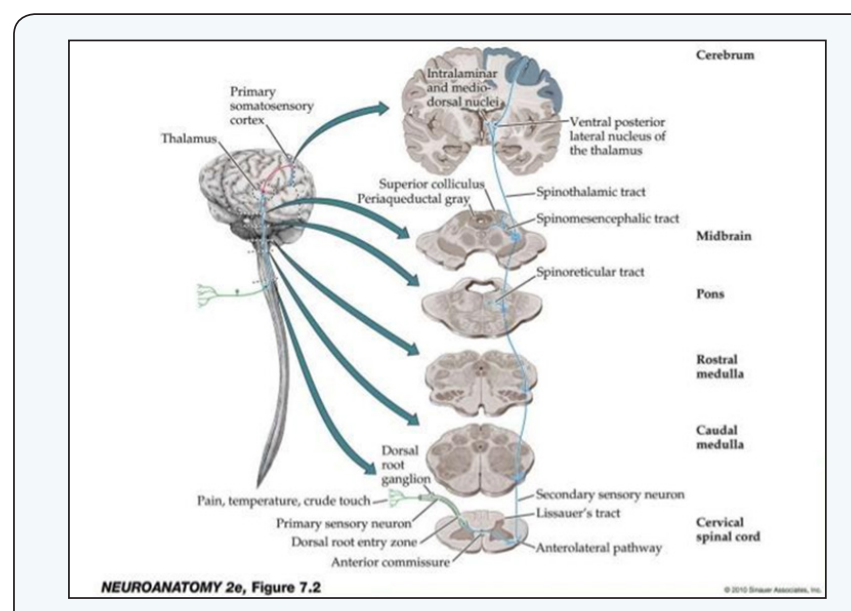

Figure 1: Neuroanatomy of brain.

Treatment for deglutition disorder involves traditional swallow therapy $[10,11]$ (diet modification, exercises to strengthen the oropharyngeal musculature, compensatory maneuvers to facilitate laryngeal elevation and closure during Deglutition, and techniques to stimulate and strengthen the deglutition reflex) and advanced VitalStim therapy. VitalStim therapy is a special form of neuromuscular electrical stimulation (NMES) device, which has received FDA clearance to be used for treatment of pharyngeal dysphagia. It can only be administered under the direction of certified healthcare professionals (speech language pathologists and occupational therapists).

VitalStim therapy is contraindicated if patient is not cooperative, unconscious, and has behavioral issues, or has any implants like pacemaker and so forth [12]. VitalStim therapy is used to re-educate the pharyngeal muscles in the throat for patterned activity to commence or re-establish deglutition in patients with deglutition disorder [10]. Vital stim electrical stimulation was theoretically proven that it may aid deglutition either by augmenting hyolaryngeal elevation or by escalating sensory input into the central nervous system. The current stimulates motor nerves in the deglutition function improves and with repetition muscles may be re-educated. The present study aims to document the severity and the advanced technological management of deglutition disorder in patient with lateral medullary infarct. We report a case of refractory deglutition disorder after Ischemic stroke and diagnosed with Right Lateral medullary Infarct.

\section{Case Report}

A 75 Years old man with specific medical history of Hypertension, Type-II Diabetic mellitus visited Medanta hospital on 10/10/2015 through Emergency room with low
GCS. Then later, patients was immediately intubated and put on mechanical ventilation support. He came with the history of acute stroke (Right Lateral medullary infarct-Right Hemiparesis with Dysarthria on 04/09/15). He was admitted at local hospital and managed accordingly. His MR Angio head \& neck vessels were normal. He was developed Right lower lobe aspiration pneumonia. Then later, he brought to Medanta Hospital for further management (Table 1).

Table 1: Risk factors, physical examination, and Neurological examination.

\begin{tabular}{|c|c|c|}
\hline Risk factors & \multirow{2}{*}{$\begin{array}{c}\text { Physical systemic } \\
\text { Examination }\end{array}$} & Neurological \\
\hline Diabetic: yes & & GCS: E1VAM1 \\
\hline Hypertension: Yes & $\begin{array}{l}\text { (at the time of } \\
\text { admission) }\end{array}$ & Gasping Respiration \\
\hline Dyslipidemia: N/A & BP: $150 / 100 \mathrm{~mm} \mathrm{Hg}$ & $\begin{array}{c}\text { Not responding to } \\
\text { painful }\end{array}$ \\
\hline $\begin{array}{l}\text { Homocysteinemia: } \\
\text { N/A }\end{array}$ & Pulse: $109 / \mathrm{min}$ & stimuli \\
\hline Atrial fibrillation/A & RR: $20 / \mathrm{min}$ & No neck stiffness \\
\hline $\begin{array}{l}\text { Valvular heart } \\
\text { disease/A }\end{array}$ & $\begin{array}{c}\text { SPO2: } 95 \% \text { ON } 02 \\
4 \mathrm{~L} / \mathrm{min}\end{array}$ & Planters both flexors \\
\hline CAD: Yes & Chest: B/L-Clear & Pupils: NSNR \\
\hline Obesity: No & CVS: S1,S2 Normal & \\
\hline Sedentary lifestyle/A & $\begin{array}{l}\text { Abdomen: Soft, Non } \\
\text { tender }\end{array}$ & \\
\hline Alcoholic: No & Temp: A febrile & \\
\hline Smoker: No & & \\
\hline
\end{tabular}

\section{Investigations}

X-RAY CHEST -05.10.2015 FINDINGS: Rotations present. Medical lines and tubes are noted. Haziness is seen in the both lower Zones and cp angles suggestive of bilateral pleural effusion with underlying atelectasis. CT BRAIN (10/10/15) CLINICAL DETAILS: Case of Right Medullary infarct and findings shows subtle hypo density noted in the right half of the medulla representing an infarct.

\section{Management of Deglutition disorder}

Phase I: An Initial clinical bed side swallow evaluation was done on the day 6 of the patient admission. The clinical bed side swallow evaluation was done with semi solid food (blended custard) along with Evens dye test with $3 \mathrm{ml} \times 4$ times via spoon and checked out for the oral and pharyngeal phases. Then the trail showed poor cough effort, weak Gag reflex, wetness in throat, frequent throat clearing and poor oral co-ordination and mastication and delayed pharyngeal phase and reduced hyolaryngeal excursion along with multiple wet swallows (5-6 times) with sever Aspiration. Then the patient was recommended 


\section{Global Journal of Otolaryngology}

to continue the RTF and graded as Level -1 based on National Outcomes Measurements Scales (NOMS). Then the patient was recommended to continue RTF and swallow therapy.

Swallow therapy was started from the day 6 for 60 minutes session for 6 days with one day off. The combined traditional swallow therapy and vital stim therapy was planned. Vital stim therapy was started with the thresholds of the patient was identified as lowest current level at which he reported "tingling sensation" on the skin. Following this the current intensity was raised to the level reported as "grabbing sensation" by the patient. In conjunction of vital stim therapy, traditional swallow therapy was provided along with sensory stimulation to elicit the swallow reflexes. Sensory stimulation therapy was done with using honey, salt, lemon drops under the supervision of Dysphagia therapist [13].

After every 6-7 days the patient has received clinical bed side swallow evaluation trail and graded accordingly based on National Outcomes Measurements Scale (NOMS) as Level-1. The patient has continuously received combined swallow therapy for 1 month and got discharged on Level 1 I.e. on RTF. On the day of discharge patient and the care taker was educated about the swallow Exercises and provided with swallow Hand-outs and recommended to continue RTF. Later, the patient couldn't follow the regular swallow Exercises.

Phase II: After 2 months the patient visited through Emergency room with the complaint of Bilateral Aspiration Pneumonia, Bilateral Pleural Effusion (right $>$ left), Right Lateral Medullary syndrome. Then again clinical bed side swallow evaluation was done on the 3rd day of admission and the results reveal poor cough effort, weak Gag reflex, fair lingual strength, wetness in throat, frequent throat clearing and poor oral coordination and mastication and delayed pharyngeal phase along with multiple wet swallows (5-6 times) with severe Aspiration and graded as Level-1 based on NOMS [14]. Then again patient has re-started with combined swallow therapy with one day off in a weak for 60 minutes sessions and recommended for intensive swallow exercises along with hand-out to practice and recommended to do intensively for 3-4 times in a day and Care taker was also educated about the same.

After 9 weeks with 54 sessions, re-swallow evaluation was done $50 \%$ of hyolaryngeal excursion was improved and still moderate aspiration was noted. Then patient was recommended for pharyngeal strengthening exercises and compensatory swallow maneuvers like shaker exercise, Mendelssohn's maneuver, effortful dry swallow were also incorporated.

After 14 weeks and 84 sessions of combined vital stim therapy and traditional swallow therapy hyolaryngeal excursion improved to $80 \%$ but still functionally weak. The clinical Bed side swallow evaluation was done with semi solid (blended custard) + dye with $3 \mathrm{ml} \times 10$ times and results reveals no Aspiration with semi solid food (blended). Then the patient was recommended for minimal oral diet (Blended diet) along with RTF and compensatory swallow maneuver like chin tuck was recommended and the patient was upgraded with Level -3 based on NOMS. Patient was recommended to avoid solid and liquid and to continue the recommended swallow exercises.

After 19 weeks and 114 sessions of combined vital stim and traditional swallow therapy the patient has achieved his $90 \%$ of hyolaryngeal function but still weakness present. The clinical swallow evaluation was done and no Aspiration noted with semi solid food and liquids. At this stage the patient was upgraded with level-5 i.e. complete oral diet with minimal food restrictions (soft blended diet with thick liquids orally was initiated). Later, on next day patient was recommended for chest X-RAY and results revealed chest clear.

After 21 weeks and 126 sessions of combined vital stim and traditional swallow therapy the patient was achieved complete oral diet and chest x-ray was done and results reveals B/L Clear chest .At that stage patient was graded with Level-7 based on NOMS.

\section{Discussion}

Lateral medullary syndrome is an uncommon stroke and we can diagnose the case clinically. Later, imaging's like (CT/ MRI of the brain) can confirm the diagnosis. Lateral medullary syndrome is commonly caused by thrombosis or embolism of the VA or PICA. Although in WS the lesion due to lateral medullary infarction is unilateral, its effect on oro-pharyngeal deglutition is bilateral. The Outlook for someone with WS depends upon the size and location of the area of the brainstem damaged by the stroke. Some individuals may see a decrease in their symptoms within weeks or months following treatment. Others may be left with significant neurological disabilities for years after the initial symptoms appeared.

Evidence of combined traditional therapy and VitalStim therapy to treat deglutition disorder due to stroke is documented [12]. Numerous researches exist on deglutition disorder management in patients with cerebral stroke, but less work has been reported worldwide on the management of deglutition disorder in brainstem stroke, especially in cases of lateral medullary infarct. One of the case studies on Deglutition disorder following lateral medullary infarct reported resolution of deglutition disorder 18 months after stroke [4]. In this study, the patient has received intensive combined swallow therapy for 1 month and could not continue for 2 months. Later, after 2 months he has developed with B/L Aspiration pneumonia and severe deglutition disorder.

Then he again started intensive combined swallow therapy under the guidance of speech therapist in Medanta -The Medicity Hospital, Gurgaon, Haryana and in only 21 weeks with 126 sessions of combined vital stim therapy and traditional swallow therapy, regardless of severe deglutition disorder with a 2 months of gap and along with late intervention, the patient has 
recovered and achieved complete ability to swallow, with liquids and normal diet orally. That is how the combined swallow therapy shows a greater effect in patients with Dysphagia. Deglutition disorder due to brainstem stroke can be managed efficiently and early intervention may help in reducing the recovery period and deglutition disorder related complications.

\section{Conclusion}

Combination of vital stim therapy and tradition swallow therapy has a greater impact on Deglutition disorder. However, further studies are needed on large number of patients with Lateral Medullary syndrome stroke to understand the recovery pattern and the impact of the early swallow therapy.

\section{References}

1. Kim H, Chung CS, Lee KH, Robbins J (2005) Aspiration subsequent to a pure medullary infarction: lesion site, clinical variables and outcome. Arch neurol 57(4): 478-483.

2. Khedr EM, Abo-Elfetoh N (2010) Therapeutic role on recovery of dysphagia in patients with lateral medullary syndrome and brainstem infarction. J Neural Neurosurgical Psychiatry 81(5): 495-499.

3. Bülow M, Speyer R, Baijens L, Woisard V, Ekberg O (2008) Neuromuscular electrical stimulation (NMES) in stroke patients with oral and pharyngeal dysfunction. Dysphagia 23(3): 302-309.

4. Aydogdu I, Ertekin C, Tarlaci S, Turman B, Kiylioglu N, et al. (2001) Dysphagia in lateral medullary infarction (Wallenberg's Syndrome) an acute disconnection syndrome in premotor neurons related to swallowing activity? Stroke 32(9): 2081-2087.

5. Kim JS, Lee JH, Choi CG (1998) Patterns of lateral medullary infarction: vascular lesion-magnetic resonance imaging correlation of 34 cases. Stroke 29(3): 645-652.
6. Aydogdu I, Ertckin C, Tarlaci S, Turman B, Kiylioglu N, et al. (2001) Dysphagia in lateral medullary syndrome (Wallenberg's syndrome). Stroke 32(9): 2081-2087.

7. Kruger E, Teasel R, Salter K, Foley N, Hellings C (2007) The rehabilitation of patients recovering from brainstem strokes: case studies and clinical considerations. Top Stroke Rehabil 14(5): 56-64.

8. Sacco RL, Freddo L, Bello JA, Odell JG, Onesti ST, et al. (1993) Wallenberg's lateral medullary syndrome. Arch Neurol 50(6): 609614 .

9. Kim JS (200) Pure lateral medullary infarction: clinical-radiological correlation of 130 acute, consecutive patients. Brain 126(Pt 8): 18641872.

10. Occupational Therapy Dysphagia Training Information (2006) Physical Medicine and Rehabilitation Department Mayo Clinic, Rochester, New York, USA.

11. M Freed, Y Wijting (2006) Training Manual for Patients Assessment, Treatment Using Vitalstim Electrical Stimulation, Chattanooga Group, Hixson, Tenn, USA.

12. Zenner PM, Losinski DS, Mills RH (1995) Using cervical auscultation in the clinical dysphagia examination in long-term care. Dysphagia 10(1): 27-31.

13. Burkhead LM, Sapienza CM, Rosenbek JC (2007) Strength-training exercise in dysphagia rehabilitation: principles, procedures, and directions for future research. Dysphagia 22(3): 251-265.

14. Hillel M Finestone, Robert W Teasell, John Heitzner (1999) Case study of dysphagia and aspiration following a brain stem stroke. Topics in Stroke Rehabilitation 6(3): 41-45.

\begin{tabular}{l} 
Your next submission with Juniper Publishers \\
will reach you the below assets \\
- Quality Editorial service \\
- Swift Peer Review \\
- Reprints availability \\
- E-prints Service \\
- Manuscript Podcast for convenient understanding \\
- Global attainment for your research \\
- Manuscript accessibility in different formats \\
( Pdf, E-pub, Full Text, Audio) \\
- Unceasing customer service \\
Track the below URL for one-step submission \\
https://juniperpublishers.com/online-submission.php \\
\hline
\end{tabular}

